\title{
SOFIA POMBA GUERRA: UMA FEMINISTA NA IMPRENSA MOÇAMBICANA DOS ANOS 1930
}

Pamela Peres Cabreira* e Luís Carvalho*

\section{Resumo}

No presente artigo, aborda-se a intervenção de Sofia Pomba Guerra na imprensa de Moçambique na década de 1930, através dos jornais O Emancipador e Notícias. Trata-se do início de um percurso de ativismo que a levará mais tarde a ter um papel de liderança na oposição à ditadura de Salazar em Moçambique e na Guiné, e a prestar um importante apoio ao Partido Africano para a Independência da Guiné e Cabo Verde (PAIGC). Agente ativa na defesa da mulher, da sua inserção social e política, a jovem Sofia protagonizará uma campanha de imprensa pelo direito ao trabalho e à igualdade económica entre homens e mulheres. Marcada pelo seu tempo e condição social, levantará questões na imprensa colonial que até então eram delegadas às falas masculinas, o que nos permite trazer como hipótese sua importância em tomar para si espaços de polémica enquanto mulher e feminista.

Palavras-chave: Sofia Pomba Guerra, imprensa colonial, mulher, trabalho, feminismo.

\section{Abstract}

Sofia Pomba Guerra: a feminist in the Mozambican Press of the 1930s

This article deals with the intervention of Sofia Pomba Guerra in the Mozambican press in the 1930s, through the newspapers O Emancipador and Notícias. It was the beginning of the activism course that would lead her later to take a leading role in the opposition to Salazar's dictatorship in Mozambique and Portuguese Guinea, and to provide an important support to the African Party for the Independence of Guinea and Cape Verde (PAIGC). Active agent in the defence of women, of their social and political integration, the young Sofia will carry out a press campaign for the right to work and economic equality between men and women. Marked by her time and social condition, she will raise questions in the colonial press that until then were delegated to the masculine speech, which allows us to hypothesize its importance in taking to herself spaces of controversy as a woman and feminist.

Keywords: Sofia Pomba Guerra, colonial press, woman, work, feminism.

\footnotetext{
* Doutoranda (Bolsista CAPES/Doutorado Pleno) em História Contemporânea, Universidade Nova de Lisboa, Instituto de História Contemporânea. Integrada no Grupo de Estudos da História Global do Trabalho e dos Conflitos Sociais, 1069-061 Lisboa. Portugal.

Endereço postal: Avenida de Berna, 26 C 1069-061 Lisboa, Portugal.

Endereço eletrónico: cabreiraperes@gmail.com

ORCID: https: / / orcid.org/0000-0002-8701-7395

Mestrando em História Contemporânea, Universidade Nova de Lisboa, 1069-061 Lisboa. Investigador do Centro de Estudos Africanos da Universidade do Porto, 4150-154 Porto. Portugal. Endereço postal: Via Panorâmica, s/n, 4150-154 Porto, Portugal.

Endereço eletrónico: luismgcarvalho@gmail.com

ORCID: https: / / orcid.org/000-0002-3139-5987
} 


\section{Résumé}

Sofia Pomba Guerra : une féministe dans la presse mozambicaine des années 1930

Cette article aborde l'intervention de Sofia Pomba Guerra dans la presse mozambicaine des années 1930, dans les journaux O Emancipador et Notícias. C'est le début d'un parcours de militantisme qui l'amènera plus tard à jouer un rôle de premier plan dans l'opposition à la dictature de Salazar au Mozambique et en Guinée Bissau, et à apporter un important soutien au Parti africain pour l'indépendance de la Guinée et du Cap-Vert (PAIGC). Agent active de la défense des femmes et de leur intégration sociale et politique, la jeune Sofia mènera une campagne de presse pour le droit au travail rémunéré et pour l'égalité économique entre hommes et femmes. Marquée par son époque et sa condition sociale, elle soulèvera dans la presse coloniale des questions jusque-là reléguées aux discours masculins, ce qui nous permet de relever l'hypothèse de son importance dans la conquête d'espaces de controverse en tant que femme et féministe.

Mots-clés : Sofia Pomba Guerra, presse coloniale, femmes, travail, féminisme.

\section{Introdução}

«Uma pessoa que teve influência no trabalho do nosso partido em Bissau, foi uma portuguesa» (Cabral 1974, 21), revelou Amílcar Cabral em 1969, num seminário de quadros do PAIGC (Partido Africano para a Independência da Guiné e Cabo Verde). Estava-se a referir a Sofia Pomba Guerra. Vários dirigentes destes dois países testemunharam o importante apoio que dela receberam: facultou formação e aconselhamento político, apresentou e aproximou militantes, ajudou alguns deles a fugir à PIDE - a polícia política. Foi em sua casa que se ensaiou o primeiro teatro africano exibido em Bissau, criticando o «sistema de dominação e exploração colonialista» (Cabral 1984, 39-40; Davidson 1988, 90-92; Lopes 2002, 49; Pereira 2002, 85). Eis uma mulher que por certo merece lugar entre as que Françoise Vèrges (2019, 31) aponta como raras feministas europeias da época que foram «resolutamente antirracistas e anticolonialistas». Contudo, Sofia continua a ser uma figura histórica pouco e mal conhecida.

Este artigo é parte de um trabalho de investigação sobre a biografia e o pensamento político que Pomba Guerra desenvolveu na África colonial portuguesa, entre 1932 e 1960 - no contexto da ditadura de Salazar. Evidencia-se aqui uma etapa inicial da militância desta mulher, a intervenção com artigos de imprensa em Lourenço Marques (hoje Maputo), Moçambique: primeiro no jornal operário O Emancipador, entre 1932 e 1936; e depois no diário generalista Notícias, em 1936.

Outros aspetos da trajetória de Pomba Guerra serão analisados em outra oportunidade, como o papel de liderança que assumiu na oposição à ditadura de Salazar em Moçambique no final da década de 1940 e na Guiné na década de 1950, e o importante apoio que prestou ao PAIGC; a repressão política de que foi vítima (presa e deportada para o forte de Caxias em Portugal em 1949/50); a sua produção literária (romance, ensaio e tradução) ou a atividade que desenvolveu como fun- 
dadora e presidente da secção feminina da Sociedade de Estudos de Moçambique (1948/49).

Maria Sofia Carrajola Pomba nasceu na cidade de Elvas, em 1906, filha de um sargento do exército que mais tarde ascenderia a capitão. Licenciou-se em Farmácia na Universidade de Coimbra, em 1929. Era uma jovem quando, em 1930, foi viver em Moçambique com o marido, Platão Guerra, e um primeiro filho ainda bebé. O que os levou a África terá sido uma motivação económica: no contexto da crise internacional que então se fazia sentir, foi ali que o marido, também formado no curso de Farmácia, conseguiu emprego ${ }^{1}$.

Radicaram-se inicialmente na vila de Tete, numa região do interior moçambicano. Em 1932, mudaram-se para Lourenço Marques. Terá sido nesta altura o encontro com o antigo jornal operário O Emancipador. Fundado em 1919, este semanário focava-se originalmente na atividade sindical e em lutas de trabalhadores em Lourenço Marques. Mas, perdida a liberdade sindical sob a ditadura, na década de 1930 passou a cingir-se à defesa da paz, do cooperativismo e da cultura. Se de início evidenciava uma ligação ao antigo Partido Socialista Português, com o tempo tomou um caráter ideológico mais difuso e plural, evoluindo para uma simpatia comunista, depois de ter passado por fases de maior influência anarquista. No período em que Sofia Pomba Guerra nele colabora, é essencialmente um jornal antifascista. Acabou encerrado pela polícia em 1937, no quadro da repressão contra o atentado a Oliveira Salazar.

Um objetivo crucial neste artigo é reconhecer o pensamento feminista de Sofia no início da sua trajetória e perceber as batalhas travadas em torno do que a sua figura representava. É necessário ter-se em conta a sua condição enquanto mulher, branca e trabalhadora num sistema colonial pulverizado em diversidades sociais, raciais e económicas.

Ao migrar para Moçambique com o marido, Sofia Pomba Guerra demoraria dez anos para também conseguir como ele um emprego na função pública, apesar de ter exatamente a mesma formação e com um alto desempenho académico. Com as suas publicações críticas nos jornais sobre o direito da mulher ao trabalho, encontra-se aqui o princípio de características que Pomba Guerra viria a revelar de forma mais visível no futuro. Argumenta-se, aqui, a relevância de conhecer e compreender as reivindicações iniciais de Pomba Guerra, sobretudo seu pensamento feminista, para perceber sua biografia e a evolução do seu pensamento, sobretudo na importância da posição marcada enquanto feminista e na defesa dos direitos das mulheres num período de autoritarismo e opressão de género ainda mais demarcados.

A jovem Sofia Pomba Guerra ainda estava longe de ser uma líder da resistência antifascista e uma importante apoiante da luta anticolonial, mas já se afirmava

Entrevista cedida por Maria Emília Pomba Baltazar (sobrinha de Sofia Pomba Guerra), Alfornelos/ Portugal, 19/02/2019. 
como defensora da emancipação feminina sob um viés feminista, sendo um exemplo de como a produção escrita de mulheres na imprensa periódica colonial ainda é um tema a ser investigado em maior profundidade. Saltando o estudo sobre mulheres literárias no contexto colonial ou mesmo de colunas específicas dentro de jornais com circulação nas colónias, e mesmo na metrópole, a problematização de género, mulher e trabalho nestes espaços ainda se mostra fecunda para novas pesquisas.

\section{As questões feministas em $O$ Emancipador}

A relação entre «trabalho assalariado» e «emancipação da mulher» é um entrelaçamento comum e marcante nos artigos escritos por Sofia Pomba Guerra, que não apenas escreve sobre terceiras pessoas, mas se coloca como agente determinante da sua experiência e da sua vida, marcadamente em artigos escritos no contexto colonial de Lourenço Marques. Ora, se Michelle Perrot está correta ao afirmar que «é o olhar que faz a História» $(2005,14)$, então, aqui, apontamos o nosso para a mulher, para o seu espaço de luta, de atuação, bem como para as contradições inerentes ao espaço colonial, tendo em consideração as características de Pomba Guerra. Ou seja, uma mulher branca, com formação superior num contexto colonial particularmente complexo e estratificado para lá da dicotomia entre europeus e africanos como era o da capital moçambicana na época. Em torno do complexo ferroviário e portuário que ali se desenvolvera para servir a África do Sul, verificava-se uma particular concentração de operariado que marcava a estratificação social entre a população europeia, no topo da qual, em termos sociais e económicos, pontificavam cidadãos ingleses. Entre a população africana havia uma camada de pequena-burguesia e de empregados com instrução escolar, considerados como «assimilados» à civilização europeia, que se diferenciavam dos trabalhadores urbanos não qualificados, porém, livres, que por sua vez se distinguiam dos trabalhadores forçados inseridos numa dinâmica de exploração versus troca de moradia, comida e trabalho. Existiam comunidades relevantes de imigrantes indianos e mauricianos, com definidas funções sociais e divisões de trabalho. A miscigenação entre moçambicanos, portugueses e indianos era outro fator de complexidade da estrutura social.

2 A partir do «Estatuto dos Indígenas Portugueses das Províncias da Guiné, Angola e Moçambique», aprovado pelo Decreto-Lei 39.666, de 20 de maio de 1954, assegurava-se que qualquer «indígena» das colónias poderia ser levado à condição de «assimilado», ou seja, inserido em «melhoramento das condições materiais e morais da vida dos indígenas, o desenvolvimento das suas aptidões [...] educação pelo ensino e pelo trabalho». A «assimilação» não se encontrava ao alcance de todos, sendo, por vezes, um entrave jurídico na ascensão social da população tradicional, onde a estratificação entre indígenas, assimilados, brancos de primeira e brancos de segunda era intensamente divisora na heterogeneidade daquela sociedade. Ver decreto completo em Ministério do Ultramar (1965). 
A partir destas considerações, discutiremos a investigação das perspetivas apresentadas tanto sobre a representação do significado da mulher trabalhadora como da construção da libertação destas mulheres, sob a ótica de Pomba Guerra nos anos 1930. Terá sido com o pseudónimo de Maria Rosa ${ }^{3}$ que começa a publicar os seus artigos no jornal operário $O$ Emancipador, questionando os motivos não apenas da mulher operária, mas de todos os trabalhadores e trabalhadoras «que de qualquer forma queiram dar à sociedade o seu trabalho, para em troca receberem aquilo que necessitam, não para o seu luxo, mas para o seu confôrto» 4 (Rosa 1932, 2). Este conforto consistia na condição de existência a partir do trabalho, uma vez que ambos, marido e mulher, manteriam a sua família com base nos seus salários. Insiste, ainda, que as mulheres compõem uma «unidade social idêntica ao homem», e o direito ao trabalho deve alcançar a todos e todas.

Neste mesmo artigo, Pomba Guerra refere-se às trabalhadoras como uma «classe» que deve «levantar a sua voz e a sua inteligência» e que, «através de todos os tempos, podemos afirmar ter sido a mais fraca e a mais oprimida: a da mulher» (Rosa 1932, 2). A sua posição demonstra a contrariedade frente à naturalização da mulher enquanto sexo frágil, apontando as barreiras a serem enfrentadas pela mulher trabalhadora. Afinal, a «classe» das mulheres foi e ainda é oprimida, mas não fraca, muito pelo contrário: esta sua marcante posição numa colónia de um país sob um regime autoritário, de cariz fascista, onde esta mulher teve por diversas vezes voz e audácia de exprimir a sua revolta e compor espaços até então tomados sempre por homens, mostra total ausência de fraqueza. Quando uma mulher neste contexto exclama que «só um regime socialista onde o subterfúgio do capital a acobertar parasitismos não exista, poderá dar a todos uma igualdade mais real que porá em foco, quando muito, diferenças naturais» (Rosa 1933a, 7), está ela mesma contrariando a ordem social e colocando-se numa posição de embate na exposição contras as diferenças sociais e económicas.

Com isto queremos dizer que artigos assinados por mulheres - com conteúdos que faziam saltar aos olhos as problemáticas sociais, questionamentos da ordem vigente e defesa da causa das próprias mulheres - são uma contestação, uma manifestação contra-hegemónica, mesmo que, por vezes, subtil. No caso de Sofia Pomba Guerra, outro elemento é interessante de ser observado: os seus artigos não compõem os espaços restritos dentro dos jornais para «as mulheres», como a «página

A identificação deste pseudónimo resulta não apenas do estudo dos artigos assinados Maria Rosa e do seu cruzamento com outros escritos de Sofia Pomba Guerra, mas também da consulta do seu arquivo pessoal guardado por sua nora, Estefânia Guerra, no qual consta uma coleção de recortes dos artigos assinados Maria Rosa juntamente com artigos assinados Maria S. Guerra, M.S. Pomba Guerra e Maria Sofia Pomba Guerra. Além disso, no próprio jornal O Emancipador $(1933,01)$ o nome Maria Rosa é identificado como sendo o «pseudónimo de uma mulher que até nós veio manifestar a sua forma de ver sôbre a posição da mulher na luta pela transformação social» (O Emancipador, 1933, 1).

4 Optámos por transcrever as citações dos artigos de Pomba Guerra como consta nos originais. 
feminina» do Notícias, onde imperavam modas e penteados e não se colocava em causa a ordem estabelecida. Por outras palavras,

as mulheres não são passivas nem submissas. A miséria, opressão, a dominação, por reais que sejam, não bastam para contar a sua história. Elas estão presentes aqui e além. Elas são diferentes. Elas se afirmam por outras palavras, outros gestos (Perrot 2006, 212).

Indo ao encontro das afirmações de Perrot, pode-se afirmar que Sofia bailou entre diferentes obstáculos e interpôs a sua voz para ser ouvida em diferentes espaços onde circulavam apenas vozes masculinas. Ao escrever sobre feminismo, direitos da mulher, trabalho e reivindicações de igualdade, afirmou-se como defensora de questões ainda secundarizadas no cenário social de Lourenço Marques.

Cabe destacar que no período vivenciado em Moçambique por Pomba Guerra, sob o domínio salazarista, se acentuava o enaltecimento das colónias africanas que já vinha do regime liberal da $1 .{ }^{a}$ República portuguesa e também a centralização da administração colonial, endurecendo a visão de inferioridade do africano enquanto «indígena» e a sua exploração com formas de trabalho forçado (Castelo 1998). Contudo, deve perceber-se a dualidade de posições frente a estas características, muitas vezes criticada por Sofia, que claramente não defendia a situação do trabalho forçado, vivenciado pelos que ela também designa como «indígenas». A limitação, se assim podemos chamar, de Sofia neste período, é não trazer para o seu brado as mulheres africanas. Ou seja, os seus artigos são essencialmente dedicados a um setor social do qual Sofia fazia parte, as mulheres que tinham acesso a alguma instrução escolar. No contexto da população portuguesa, isso já significava uma minoria. Mas no contexto colonial constituía um setor muito mais minoritário e marcado «racialmente», de mulheres brancas, mestiças e assimiladas. Não incluía a grande maioria: as mulheres negras, que sofriam uma exploração brutal, fosse nas plantações de algodão, chá e tabaco, ou em funções urbanas de serventia ou mesmo na indústria (Hedges et al. 1993, 54).

Pela ênfase na emancipação económica e profissional, e pelo alinhamento da luta pela emancipação feminina com uma perspetiva de transformação social mais lata, a análise de Sofia Pomba Guerra na década de 1930 distingue-se do feminismo sufragista, pautado sobre as individualidades e luta pelos direitos jurídicos, mas não uma mudança da estrutural social (Álvares 2002), que era o que Pomba Guerra defendia já nesta altura. Mas o facto desta sua análise se centrar numa população essencialmente urbana e escolarizada - ou seja, fundamentalmente branca e tão minoritária na sociedade laurentina da época - já parece moldada nas limitações do «feminismo ocidental», que seria mais tarde criticado "por tentar universalizar a experiência de mulheres brancas (em geral de classe média) em países capitalistas avançados» e partilhará do «fracasso do feminismo branco em se engajar nas questões do racismo e do etnocentrismo» (Barret 1991,189; Barret 1996, 306). 
Essas perspetivas críticas do feminismo e a perceção das mulheres não como uma categoria homogénea mas, sim, fragmentada, nomeadamente por diferenças de raça e de etnia, só se desenvolveriam mais tarde, na década de 1970 (Soihet 1997, 399).

Já em 1933, Pomba Guerra, ainda sob o seu pseudónimo de Maria Rosa, indica a importância do trabalho para a mulher, onde o

início das aquisições femininas deve começar pela libertação económica. Sem essa independência a mulher será a eterna coagida. Como base de toda a emancipação batalhemos pela igualdade perante o trabalho: igualdade de acesso e de salário perante igualdade de aptidões (Rosa 1933b, 5).

Esta atribuição de primazia à libertação económica como base para outras libertações revela uma similitude com a perspetiva que Bento de Jesus Caraça apresenta na sua célebre conferência sobre a cultura integral do indivíduo, considerando como «condição indispensável para que o homem possa trilhar a senda da cultura - que ele seja económicamente independente» (Caraça 1933, 40).

Com uma série de artigos intitulados «maneiras de ver de uma mulher», Sofia Pomba Guerra irá tratar de temas diversos, mas, sobretudo, sobre a condição da mulher trabalhadora, da educação profissionalizante, socialismo, feminismo e temas religiosos, por vezes pincelados em diferentes tons, além de responder a algumas críticas mais «masculinistas» sobre os seus artigos.

A defesa da profissionalização é uma constante. Sofia Pomba Guerra defendia que apenas através do trabalho a emancipação da mulher seria possível. Destaca que o direito das raparigas de «serem preparadas para o desempenho duma profissão, de serem colocadas em face da vida como unidades activas e conscientes e não como objectos que deixaram a tutela dos pais para se sujeitarem ao mando dos maridos», e, portanto, «sem liberdade económica não há vontade própria, raciocínio inteligente, ou fortaleza de carácter, mas somente servilismo e tibieza» (Rosa 1933c, 6). Em contrapartida, Pomba Guerra faz uma crítica à «liberdade sexual da mulher» como o caminho para a sua emancipação. Defende, com maior intensidade que

a verdadeira emancipação da mulher tem por base a emancipação económica, uma pobre diabo sem vintém não pode dar-se ao luxo de ter ideias suas, e a que lhe seguisse os conselhos sem ter curado disso, iria simplesmente ter à prostituição (Rosa 1934a, 1).

Essa crítica sobre um livro chamado Liberdade Sexual da Mulher, em que afirma que o livro toma duas conclusões erróneas e precipitadas: «a que a emancipação sexual é a verdadeira emancipação da mulher, a que o direito a subordinar os apetites sexuais só ao sabor dos caprichos é o único ideal de viver» (Rosa 1934a, 1). Além da sua defesa de um viés económico para um processo de independência da 
mulher, cabe ressaltar que Sofia assenta determinados valores na família, na fidelidade e nas relações que rondam essa instituição que é o casamento. Ainda assim, não deixa passar neste artigo uma crítica, não à autora do livro que não é mencionada, mas, sim, a uma senhora que escreve uma crítica ao tal livro pedindo a sua censura; o artigo de Pomba Guerra centra-se, portanto, mais na crítica sem reflexão, indagando-se «como haverá consciência e convicção onde escasseia a liberdade?» (Rosa 1934a, 1).

\section{2. «O trabalho da Mulher» e a emancipação feminina}

No ano de 1936, e já assinando os seus artigos como Sofia Pomba Guerra, o jornal diário Notícias trará uma série chamada «O Trabalho da Mulher», composta por 18 artigos ao longo de seis meses sobre o direito da mulher ao trabalho. O seu lema mais marcante nesta composição será «a mulher tem direito ao trabalho e à igualdade de acesso e de salário em face da igualdade de aptidão» (Guerra 1936a, 3). A partir do protesto pelo direito ao trabalho e de que apenas com a independência económica a mulher conseguirá ver-se livre das «conveniências sociais» (1936a, 3), Sofia Guerra inicia uma empreitada em mapear em que «condições trabalha a mulher em Moçambique, como lhe é reconhecido ou vedado o direito ao trabalho [...] as condições de cooperação ou atrito que encontra nos seus camaradas e chefes» (1936a, 3). Considera, a partir destes objetivos, a diferença entre o trabalho nos serviços de Estado e em empresas particulares:

No primeiro caso o direito ao trabalho depende dele ser reconhecido pela colectividade ou antes pelo Estado, que nem sempre a representa, é portanto uma doutrina aceite e aplicada. Isto teóricamente, porque na prática ainda o grande reconhecimento doutrinário é o tal plano inclinado a que se chama cunha individual.

Nas emprêsas particulares, que têm por móbil o lucro, a aceitação de mulheres depende do seu valor como produtores de trabalho, ou, o que é mais vulgar, dos interesses que dão à emprêsas, pelos baixos salários com que em geral se contentam (Guerra 1936a, 3).

Visando a Constituição e 1933, que consagra a ditadura de Salazar, Sofia Guerra irá criticar fortemente as «brechas» que são construídas justamente para impedir ou diminuir a importância das mulheres nos cargos geridos pelo Estado. Segundo ela, na Constituição, que «parecia investir a mulher nos seus plenos direitos de igualdade de trabalho com o homem essas barreiras mantêm-se, parecendo que aquele reconhecimento foi apenas passagem de mel pelos beiços, que de resto muitas se têm apressado a lamber com entusiasmo» (Guerra, 1936a, 3). Esse «mel», recusado por Pomba Guerra, fará com que ela problematize alguns segmentos, como nos Serviços Administrativos, Serviços de Fazenda, Serviços dos Correios e Telégrafos, 
Serviços de Agricultura, Obras Públicas, Serviços de Estatísticas, Serviços de Instrução, Ensino Secundário, Serviços de Saúde, Comércio. A estratificação social em Lourenço Marques não apenas definia quem e onde iriam trabalhar, mas também onde homens e mulheres eram mais «adequados» para determinados tipos de trabalho. Sofia Guerra nesta secção sobre o trabalho feminino será muito contundente ao defender que as mulheres estão aptas a desempenhar qualquer função que seja, recebendo os mesmos salários dos homens. Mas ao focar, sobretudo, mulheres que trabalhavam no Estado, no comércio e nos serviços, estava a categorizar uma realidade de mulheres brancas, deixando passar ao lado a vida das mulheres africanas.

Sobre o mercado de trabalho feminino e as disposições sobre igualdade sexual no emprego, Perrot aponta que «as discriminações de fato enraízam-se nos costumes, produtos de representações de longa duração, remodeladas ao sabor das necessidades do tempo» $(2005,251)$; determinantes que também encontramos na sociedade de Lourenço Marques na década de 1930 e marcada nas diversas intervenções de Sofia Guerra.

Dentro destes setores, vários aspetos serão abordados. Mapeamos as seguintes críticas e reivindicações que são repetidas ao longo da série e que nos parece primordial para compreendermos a importância da sua luta, muitas vezes subtil e tantas outras diretas e incisivas: cargos inferiores preenchidos apenas por mulheres e com salários inferiores; salário igual para funções iguais; parcialidade na escolha de cargos após provas práticas, excluindo as mulheres; educação e formação profissional igual para homens e mulheres; não elevação a cargos de chefia, mesmo em situações de «merecimento»; contra a exclusão das mulheres em cargos de direção em escolas. Sempre enfatizando que o trabalho fora de casa é o caminho para a emancipação da mulher e que o ensino profissionalizante para as «raparigas» deve ser levado em conta sempre pela família, Sofia incute nesta datada sociedade um discurso e questões que proporcionam pensamentos e reflexões fora da «hierarquia vigente».

No mês de setembro de 1936, a proposta da farmacêutica Pomba Guerra volta-se para a realização de conversas com diferentes trabalhadoras, mas, como se referiu, dentro do setor de mulheres com acesso a instrução escolar, essencialmente europeias. Anuncia que esta é a «primeira duma série de entrevistas» (Guerra 1936b, 3), mas, por motivos desconhecidos, apenas quatro serão publicadas, com duas empregadas comerciais, uma médica e uma professora. Logo na primeira entrevista, defende que

é uma obrigação moral de todas nós, as mulheres para quem a vida é menos dura, batalhar pela causa da mulher, por aquelas que apanhadas do improviso num cotovelo da vida, não têm quem levante a voz pelos seus direitos (Guerra 1936b, 3).

Dito isto, traça algumas perguntas fundamentais e que repetirá nas quatro entrevistas, além das que surgem espontaneamente. Era de seu interesse que estas 
mulheres opinassem sobre o direito da mulher ao trabalho remunerado; sobre a educação profissional às raparigas; quais as impressões dos colegas de trabalho; se consideravam que as mulheres são mais mal remuneradas que os homens; se elas sentem a vontade em trabalhar fora de casa e, finalmente, se consideram que as mulheres têm o direito de tomar parte em assuntos políticos.

De formas mais ou menos acentuadas, as quatro entrevistadas mostram-se defensoras dos pontos levantados por Sofia Pomba Guerra. Todas reportam que trabalham fora de casa e mantêm o trabalho doméstico em ordem, bem como acham indispensável a formação das mulheres numa dada profissão. Apenas a primeira entrevistada se mostrou mais reticente quanto a estas questões, ao afirmar que «há, porém, profissões para que, julgo, a mulher nunca se poderá habilitar como o homem» (Guerra 1936b, 3) ou, quando perguntada sobre cargos de responsabilidade, responde que o homem «está, em geral mais preparado e tem mais energia. Nos trabalhos inferiores a mulher é mais persistente e paciente que o homem. Além disso, é desagradável para o homem estar debaixo das ordens duma mulher. Sente-se mal» (Guerra 1936b, 3). Uma das entrevistadas inicia a conversa dizendo que «é sempre com verdadeiro prazer que leio os seus artigos. Diz neles grandes verdades» (Guerra 1936c, 5). Ao expressar estas ideias num jornal diário de grande expressão na capital moçambicana, como o Notícias, a jovem Sofia Guerra estava a fazer circular uma problematização de questões até então dadas como socialmente aceitas e legitimadas, ou seja, o lugar da mulher era em casa, a cuidar da casa, filhos e marido. Sofia Pomba Guerra introduzirá na imprensa local questões que desvendam problemas pelos quais ela mesma passava, em não conseguir empregos adequados por setores de formação ou que aceitassem mulheres de acordo com as suas aptidões. A quebra do socialmente aceite e legitimado dá-se, sobretudo, por recusar a diminuição da mulher ao papel de dona de casa e pela defesa dos direitos e da igualdade, caros a um feminismo que ganha forças no início do século XX e no qual Sofia se iniciava. $\mathrm{O}$ «feminismo socialista» basear-se-á na defesa de um regime de igualdade e da situação da mulher trabalhadora como chave na compreensão da necessidade de mudanças estruturais na sociedade. Tal como Sofia viria a defender no início de 1930, Flora Tristan abordaria, na sua obra União Operária (1843) a educação como essencial no progresso da classe trabalhadora e na vida da mulher, sem, entretanto, fazer uma divisão crítica do trabalho doméstico, por exemplo.

Sofia Guerra defende a todo o instante que as mulheres têm o direito ao trabalho, que esse é o caminho para se emanciparem das amarras sociais, porém, não incorre em retirar a mulher da esfera privada e do trabalho doméstico. Em diversas passagens, aponta que é possível relacionar os dois, nomeadamente com a ajuda da tecnologia que colabora com a diminuição do tempo gasto nesta tarefa. De forma mais direta, num artigo de 1933, tomou os seguintes apontamentos:

A mulher, se quer ter igualdade de ingresso na vida política e na produção, no primeiro caso afirmando a sua individualidade, no segundo garantindo a sua liberdade econó- 
mica e possivelmente a de seus filhos, não desdenha a sua qualidade de dona de casa nem repudia, já não digo a sua obrigação, mas o seu direito de ser mãe. [...] Nem todos os trabalhos que uma casa requer podem ser socializados e o serviço doméstico é constante e impreterível. À mulher, que tenha produzido externamente o mesmo valor de trabalho que o homem, chega a casa e tem ainda muito que fazer. Produz portanto um trabalho total superior ao homem (Rosa 1933d, 3).

Uma nota a salientar nos artigos de Sofia são as evidências de leituras marxistas e alguma proximidade, mesmo que crítica, com questões socialistas. Para além de artigos que rondam a situação da União Soviética ou mesmo da relação socialismo/comunismo, Pomba Guerra (1936a, 3; 1936d, 3) assume e valoriza o marxismo como instrumento de análise da condição feminina e das vias para a sua emancipação. É de marxismo que fala quando considera o «factor económico» como «factor primordial da evolução» social e defende a «veracidade do materialismo histórico nas grandes linhas gerais». O que a leva a considerar que «a emancipação feminina seria inexequível apenas escorada em princípios teóricos [...] senão tivesse a auxiliá-la, e mesmo a empurrá-la, um mecanismo social tornado apto pela perfeição da técnica de produzir» e anular a diferença de força física entre homens e mulheres (Guerra 1936d, 3).

Subtilmente, Pomba Guerra traceja em muitos de seus artigos componentes de uma proximidade crítica com o socialismo, seja entre o feminismo socialista utópico como referido anteriormente, seja com o feminismo mais tracejado ao socialismo marxista, ou seja, que problematizava a opressão da mulher e as suas vias de emancipação. Sobretudo a partir da obra de Friedrich Engels, A Origem da Familia, da propriedade privada e do Estado (1884), esta vertente decorreria na emancipação das mulheres ao retorno à produção e seu controle bem como à independência económica (Álvarez 2002, 30), tão caros a Pomba Guerra.

Ainda em 1934, escreverá um artigo sobre a família no socialismo, admoestando a radicalidade de Alexandra Kollontai sobre a mulher ter que abandonar o lar e a obrigatoriedade maternal para se dedicar à revolução (Rosa 1934b, 8). Para Pomba Guerra, essa recusa «natural» só teria a perder para a luta das mulheres. $\mathrm{Na}$ série de 1936 no jornal Notícias, as três últimas reportagens tratam exatamente o trabalho doméstico, e aqui vemos uma abertura para novas problematizações sobre o paradigma do trabalho assalariado e doméstico.

Nestes três artigos, Pomba Guerra irá analisar o trabalho doméstico sob uma perspetiva económica, produtiva e familiar. A sua visão, antes tão «protetora do lar», é agora problematizada pelas condições a que este trabalho serve na sociedade. De forma generalizada e até mesmo otimista, Guerra afirma que «hoje, tôdas as doutrinas económicas de importância concordam que o valor de determinado trabalho não é apenas função do tempo empregado, mas também proporcional ao valor intrínseco que êsse trabalho representa para a unidade de tempo»e, por fim, «há, pois, um valor de trabalho e uma duração de trabalho» (1936e, 5). Ora, ao cotar 
ao serviço doméstico um valor de produção e ao dizer que este trabalho é praticamente realizado apenas pelas mulheres, Sofia Pomba Guerra mostra um salto sobre o problema para além do trabalho doméstico familiar, considerando também a mulher doméstica que o faz enquanto profissão, trabalhando para outros. Ao comparar o salário de um / a professor / a, determina que trabalhando o mesmo número de horas, uma assalariada doméstica recebe oito vezes menos. E conclui que «mais de metade dos indivíduos humanos, obrigados unicamente a trabalhos domésticos, limitam-se a produzir uma diminuta fracção do valor total da produção, são uns párias sociais sob o ponto de vista económico, representam um desperdício de energia» (Guerra 1936e, 5). Sofia Guerra aqui não aponta a dispensa do trabalho reprodutivo como economicamente dispensável, mas, sim, que o trabalho doméstico quando «terceirizado» como empregatícia, isso sim, como ela própria diz, é uma perda de uma função energias. Ainda longe de uma dicotomia entre trabalho reprodutivo e produtivo, substanciados pelo que Cunha irá traduzir como uma «invenção poderosa da tríade de opressão: capitalismo, colonialismo e patriarcado» $(2015,156)$, Sofia Pomba Guerra determina que todo este trabalho tem um valor monetário, ou seja, é trabalho produtivo.

«Sendo um trabalho que quási não necessita preparação ou exigindo apenas o mínimo de destreza [...] é o trabalho das mulheres das classes pobres. [...] É um trabalho de miséria» (Guerra 1936f, 7). Sofia Pomba Guerra faz aqui um paralelo entre as sociedades mais desenvolvidas que, criando condições de instrução às classes mais baixas, tendem a diminuir ou extinguir o trabalho doméstico assalariado. Claro que o seu discurso é condicionado por situações ainda não concretas, copiosamente insistindo em uma não quebra de barreiras sociais para a inserção dos negros em "condições iguais de instrução", como acreditava Sofia, que também parece deixar de lado, a partir desta problematização mais economicista, as mulheres que continuavam a ser domésticas e não ultrapassavam a barreira de sair do lar.

Os artigos e as polémicas levantadas por Sofia Pomba Guerra claramente não passaram despercebidos na sociedade moçambicana. Muitos artigos foram redigidos a contracorrente das expressões e posições que circulavam na imprensa nos mais diferentes meios, mas não só. Publica um livro em 1935, o Dois anos em África (Guerra 1935) que irá render-lhe das mais simpáticas às mais agressivas críticas à sua escrita, conteúdo e métrica literária. Destes vários artigos, um salta à vista: em julho de 1936, o jornal União, órgão da União Nacional em Moçambique/Lourenço Marques publicará um artigo que expressa significativamente o ideal masculino, e claro, também de algumas mulheres, sobre a presença de Sofia na imprensa moçambicana e o desprezo por uma voz feminina ter espaço no jornal Notícias. Recorrendo a uma crítica do jornal Diabo demasiadamente negativa - mas não ofensiva por ter sido uma mulher a escrevê-la - a redação do União intitula o artigo de «Nem o Diabo quer nada com ela...» e afirma que «a sr. ${ }^{a}$ Pomba Guerra, a quem já ouvimos chamar «Chefe das milícias femininas», é realmente uma pessoa muito diver- 
tida pela actividade revolucionária feminina que está desenvolvendo nesta capital da Provincia de Moçambique», e, sobre a sua série no Notícias sobre as mulheres e os diversos campos de trabalho, ataca: «a mulher em toda a parte, menos em casa a tratar dos filhos, que parece ser o logar onde a sr. ${ }^{a}$ D. Guerra, não quere estar», por fim, diz «á sr. D. Pomba, que se deixasse da propaganda feminista que anda fazendo e tratasse d'aquilo que toda a mulher casada e com filhos, deve tratar» (União 1936, 2). Aqui é clara a aversão e até mesmo o sentido de receio sobre o que a sua posição podia significar para leitoras do seu livro e das suas colunas nos jornais. A contraversão da ordem sempre foi temida por quem domina.

A luta pelo direito da mulher ao trabalho e à igualdade económica entre homens e mulheres aparece como a grande prioridade de Sofia Pomba Guerra nesta primeira fase de militância com artigos de imprensa em Lourenço Marques. Outra preocupação mais visível é a defesa da paz e também transparecem as suas convicções democráticas. Mas, nos anos 1930, a futura apoiante do PAIGC ainda não tinha superado o que Françoise Vèrges caracteriza como «feminismo ocidental», «ambivalente ou indiferente à questão racial e colonial» $(2019,11)$.

O espírito de lutadora, esse já se revela:

A luta foi bem mais árdua, porque é mais trabalhoso romper a primeira brecha num edifício ainda sólido do que dar uma martelada naquele que já por todos os lados se esboroa. É necessário perseverança, culto pelo trabalho e coragem (Guerra 1936d, 3).

\section{Conclusões}

A reconfiguração das lutas e perspetivas dos «feminismos» ao longo do século XX foi-se gradualmente adequando também às condições sociais, políticas e económicas em que os agentes históricos estavam inseridos, tendo como motor das reivindicações as suas próprias realidades sociais. A década de 1930, período em que se inicia a militância de Sofia Pomba Guerra, estava fortemente marcada por dicotomias no espectro das lutas pela igualdade, pela emancipação através da independência económica, bem como pelas problematizações sociais em torno do entre guerras, sobretudo as diretrizes imperialistas e políticas coloniais.

Ao trazer para o debate uma personagem histórica, filha do seu tempo mas que desafiava a normalidade e homogeneidade social, há que ter em conta o que se pode aprender com o início da trajetória de Maria Sofia Guerra e o que ela nos demonstra.

Neste sentido, o pensamento e a militância de Sofia Guerra são compreendidos como algo dinâmico, que evoluiu ao longo do tempo, como um processo de aprendizagem e radicalização ideológica a partir da experiência e envolvimento político. Nos anos 1950, a veterana Sofia Guerra foi uma importante apoiante da luta anticolonial. Contudo, o período analisado mostra uma jovem que não ia além de 
um «feminismo ocidental», «ambivalente ou indiferente à questão racial e colonial» (Vèrges 2019, 11). Entretanto, os seus artigos em prol da emancipação das mulheres, dos direitos à educação e profissionalização, bem como, muitas vezes, a independência frente ao marido, já mostravam a capacidade combativa e intelectual desta mulher numa época e contexto social em que compactuar com o estabelecido era mais fácil do que mostrar as garras e sujeitar-se a críticas e represálias.

\section{Referências bibliográficas}

Álvares, Ana de Miguel. 2002. O feminismo ontem e hoje. Lisboa: Ela por Ela.

Barret, Michèle. 1991. «Feminism». In A Dictionary of Marxist Thought, edited by Tom Bottomore, 189-190, second edition. Oxford: Blackweel Publishing.

Barret, Michèle. 1996. «Feminismo». In Dicionário do Pensamento Social do Século XX, editado por William Outhwaite e Tom Bottomore, 304-307. Rio de Janeiro/Lisboa: Jorge Zahar Editor/Dinalivro.

Cabral, Amílcar. 1974. Alguns princípios do Partido. Lisboa: Seara Nova.

Cabral, Luís. 1984. Crónica da libertação. Lisboa: Edições «O Jornal».

Caraça, Bento de Jesus. 1933. A Cultura Integral do Indivíduo. Lisboa: Edições Mocidade Livre.

Castelo, Cláudia. 1998. Recepção em Portugal da doutrina de Gilberto Freyre. O Modo Português de Estar no Mundo. O Luso-Tropicalismo e a Ideologia Colonial Portuguesa (1933-1961). Porto: Edições Afrontamento.

Cunha, Teresa. 2015. «Women inPower Women». Outras economias criadas e lideradas por mulheres no sul não-imperial. Buenos Aires: CLACSO. Disponível em http: / / biblioteca.clacso.edu. ar/clacso/sur-sur/20150911112429/Women.pdf

Davidson, Basil. 1988. As ilhas afortunadas: um estudo sobre a África em transformação. Lisboa: Editorial Caminho

Guerra, Maria Sofia Pomba. 1935. Dois anos em África. Edição da Autora.

Guerra, Maria Sofia Pomba. 1936a. «O trabalho da mulher». Notícias, de 25 de maio. Cota J.4165 G. Arquivo Biblioteca Nacional de Portugal.

Guerra, Maria Sofia Pomba. 1936b. «O trabalho da mulher - primeira duma série de entrevistas». Notícias, de 21 de setembro. Cota J.4165 G. Arquivo Biblioteca Nacional de Portugal.

Guerra, Maria Sofia Pomba. 1936c. «O trabalho da mulher - Entrevista com a Dra. Sousa Lôbo». Notícias, de 28 de setembro. Cota J.4165 G. Arquivo Biblioteca Nacional de Portugal.

Guerra, Maria Sofia Pomba. 1936d. «O trabalho da mulher IV - A preparação da mulher e a educação do homem». Notícias, de 15 de junho. Cota J.4165 G. Arquivo Biblioteca Nacional de Portugal.

Guerra, Maria Sofia Pomba. 1936e. «O trabalho doméstico». Notícias, de 30 de novembro. Cota J.4165 G. Arquivo Biblioteca Nacional de Portugal.

Guerra, Maria Sofia Pomba. 1936f. «O trabalho doméstico II». Notícias, de 2 de dezembro. Cota J.4165 G. Arquivo Biblioteca Nacional de Portugal.

Hedges, David, Aurélio Rocha, Eduardo Medeiros, Gerhard Liesegang, e Arlindo Chilundo. 1993. «História de Moçambique, vol. 3, Moçambique no auge do colonialismo, 1930-1961». Disponível em http:/ / psimg.jstor.org/fsi/img/pdf/t0/10.5555/al.sff.document. crp2b20002_final.pdf [Consultado em 20 de novembro de 2018]. 
Lopes, José Vicente. 2002. Cabo Verde - os bastidores da independência. Cidade da Praia: Edições Spleen

Ministério do Ultramar. 1965. «Decreto-Lei 39 666, de 20 de maio de 1965». In Diário da República, 110, I Série, 560-565. Disponível em https: / / dre.pt/application/conteudo/635399. [Consultado em 15 de fevereiro de 2019].

O Emancipador, 1933. «A nossa admiração pela Rússia», O Emancipador, de 2 de janeiro. Cota F.2563-66. Arquivo Biblioteca Nacional de Portugal.

Pereira, Aristides. 2002. Uma luta, um partido, dois países. Lisboa: Editorial Notícias.

Perrot, Michelle. 2005. As mulheres ou os silêncios da história. Bauru, SP: Editora da Universidade do Sagrado Coração.

Perrot, Michelle. 2006. Os excluídos da história: operários, mulheres e prisioneiros. 4. ${ }^{\text {a }}$ ed. São Paulo: Editora Paz e Terra.

Rosa, Maria. 1932. «A questão social: Maneiras de ver de uma mulher». In O Emancipador, de 19 de dezembro. Cota F.2563-66. Arquivo Biblioteca Nacional de Portugal.

Rosa, Maria. 1933a.«Maneiras de ver de uma mulher». O Emancipador, de 16 de janeiro. Cota F.2563-66. Arquivo Biblioteca Nacional de Portugal.

Rosa, Maria. 1933b. «Maneiras de ver uma mulher». O Emancipador, de 06 de fevereiro. Cota 2563-66. Arquivo Biblioteca Nacional de Portugal.

Rosa, Maria. 1933c. «As obrigações da mulher». O Emancipador, de 20 de novembro. Cota 2563-66. Arquivo Biblioteca Nacional de Portugal.

Rosa, Maria. 1933d. «Maneiras de ver de uma mulher - A mulher dona de casa e mãe». O Emancipador, de 1 de maio. Cota F.2563-66. Arquivo Biblioteca Nacional de Portugal.

Rosa, Maria. 1934a. «Liberdade sexual da mulher». O Emancipador, de 26 de março. Cota F.2563-66. Arquivo Biblioteca Nacional de Portugal.

Rosa, Maria. 1934b. «A família no socialismo». O Emancipador, de 22 de janeiro. Cota F.256366. Arquivo Biblioteca Nacional de Portugal.

Soihet, Rachel. 1997. «História das Mulheres». In Domínios da história - ensaios de teoria e metodologia, coordenado por Flamarion Cardoso, e Ronaldo Vainfas. Rio de Janeiro: Editora Campus.

União. 1936. «Nem o 'Diabo' quer nada com ela...». In União, de 15 de julho. Arquivo Biblioteca Nacional de Portugal.

Vèrges, Françoise. 2019. Um féminisme décolonial. Paris: La Fabrique éditions.

Pamela Peres Cabreira. Doutoranda (Bolsista CAPES/Doutorado Pleno) em História Contemporânea - Universidade Nova de Lisboa, Instituto de História Contemporânea. Integrada no Grupo de Estudos da História Global do Trabalho e dos Conflitos Sociais.

Endereço eletrónico: cabreiraperes@gmail.com

Luís Carvalho. Mestrando em História Contemporânea - Universidade Nova de Lisboa. Investigador do Centro de Estudos Africanos da Universidade do Porto.

Endereço eletrónico: luismgcarvalho@gmail.com

Artigo recebido a 27 de novembro e aceite para publicação a 4 de março de 2019. 